\title{
THE IMPACT FOR RETAILER'S POLICY IN SUPPLY CHAIN SYSTEM UNDER TRADE CREDIT AND QUANTITY DISCOUNTS
}

\author{
Tien-Yu Lin*, Ying-Chun Li And Q.-S. Li
}

\begin{abstract}
This paper develops a powerful retailer inventory model under trade credit and quantity discounts in which the retailer's order quantity is calculated for each setup and shipped in equal lots over multiple deliveries. Furthermore, the trade credit condition is that the retailer must make partial payments in cash for a given number of sub-shipments, with the remaining balance paid in trade credit time that expires after the inventory is depleted. This integrated powerful retailer supply chain model has not yet been discussed in previous supply chain coordination systems literature. We propose an annual total cost function and properties and develop theorems to illustrate that a unique optimal solution minimizes the relevant cost per year. We also develop an efficient algorithm to determine the optimal set of the replenishment time and the number of shipments. Numerical examples are provided to demonstrate the proposed model and algorithm. A sensitivity analysis is explored to examine the effects of four important parameters (i.e., setup cost, unit holding cost, interest rate, and receiving cost) on the optimal strategy. Finally, managerial insights are drawn.
\end{abstract}

Mathematics Subject Classification. 90B05, 91B06, 90B30.

Received August 3, 2019. Accepted October 11, 2020.

\section{INTRODUCTION}

The retail industry is today increasingly dominated by "powerful" retailers in a dominant position that enables them to squeeze and pressure their suppliers by taking expensive actions (e.g., lowering prices, accelerating delivery times, and offering special allowances). Such actions might coerce suppliers deficient in bargaining power to be easily forced to provide "giant" retailers with concessions that are financially harmful to the suppliers themselves. This situation exists in the grocery industry (e.g., Wal-Mart). Specifically, a retailer exerts power over its supplier using certain mechanisms (e.g., trade credit, quantity discounts, and lot-splitting shipments) in which the buyer and supplier formulate coordinating mechanisms to maintain their partnership.

One of the most common coordination mechanisms for a retailer and supplier is trade credit, which allows a buyer to settle its balance with a supplier using an interest-free period. Trade credit is recognized as an effective incentive and coordination contract that is widely used in various industries in China, the United States, and Europe $[10,19,38]$. In recent years, the issue of trade credit has received considerable attention from scholars and practitioners (e.g., $[5,9,11,12,14,26])$. In general, there are two main categories for contract formulation of trade credit: one-part and two-part trade credit [36]. In one-part trade credit, a seller permits a buyer to delay

Keywords. Supply chain management, trade credit, quantity discounts, lot-splitting shipments.

School of Economics and Management, Sanming University, Sanming 365004, Fujian, P.R. China.

*Corresponding author: 3146375768@qq.com 
payment for a certain duration without incurring any interest charges. The first proponent of this sub-issue was Goyal [11], who developed an economic order quantity (EOQ) model for a retailer who receives a permissible delay in payment for a fixed time period from a supplier. Under this research stream, several studies extending Goyal's work were developed. For example, researchers extended his work to the topics of deteriorating goods (e.g., $[1,20,28])$ and shortages (e.g., $[4,13,21])$. Other researchers developed an inventory model in which they employed one-part trade credit policy linked to order quantity $(e . g .,[4,6,31])$. Other related extensions with one-part trade credit can be found in Tiwari et al. [27], Ries et al. [24], Tsao [30], Cao and Yu [3], Tiwari et al. [28], Yang et al. [35], and many others.

Although one-part trade credit provides simple and intuitive advantages for a buyer, it leads to a seller facing accelerating default risk and reducing cash flow. To balance the risk between the buyer and seller, two-part trade credit, in which a seller offers a policy to a buyer in which he or she can make full payment either within a short duration (say, $M_{1}$ ) at a discount rate (say, $\lambda$ ) or within a longer duration (say, $M_{2}$ ) at no price discount, was developed. Linking two-part trade credit, which could increase cash flow and decrease default risk, to the EOQ model was first done by Huang and Chung [15]. Afterward, many researchers explored the two-part trade credit scheme. Some (e.g., $[7,22,25])$ investigated a retailer or an integrated supplier-retailer inventory model in which they considered two-part trade credit being linked to optimal lot size. Other variant studies related to two-part trade credit are Cárdenas-Barrón et al. [4], Chung et al. [8], and Liao et al. [17]. We note that the above studies based on the conventional two-part trade credit model did not meet practice; especially, when a buyer has bargaining power to squeeze the seller. Thus, with the flexible two-part trade credit scheme, a seller requests that a buyer to pay a certain purchasing cost at a cash discount within a given duration and then to pay the remainder, enjoying the price discount until the maturity date. There are few related papers in the literature. Zhou et al. [37] proposed a mathematical formula to determine the optimal lot size and payment scheme under two-part flexible trade credit, in which the retailer benefits more than in the traditional payment scheme. Yang et al. [34] considered a two-period supply chain model with flexible trade credit in which the supplier provides the benefit of a discounted price for the second order to strengthen the retailer choosing early payment during the first period. Their results indicated that flexible trade credit contracts can increase decentralized supply chain efficiency and decrease suppliers' trade credit risk. Zou and Tian [39] employed twopart and two-level trade credit schemes to determine a retailer's optimal ordering and payment policy in which the upstream trade credit is a flexible two-part trade credit and the downstream trade credit is a one-part trade credit. All of the previous papers mentioned above assumed that the length of the trade credit is independent of order quantity. However, Tiwari et al. [29] discovered that the larger the amount ordered, the better the trade contract a supplier can offer to increase the credit duration to ease the retailer's financial situation. They therefore proposed an EOQ model for determining items under order-size dependent trade credits and allowable backorders. Although Tiwari et al. [29] noted the relationship between trade credit and order lot size, they did not discuss the relationship between quantity discounts and trade credit. Suppliers, in general, offered retailers' trade credit and/or quantity discounts to decrease on hand inventory levels, increase sales, achieve economic scale, and attract new customers. Wang and Liu [32] therefore proposed a hybrid analytical model combining trade credit and quantity discounts to coordinate the supply chain by motivating retailers to increase product order quantity. Their results illustrated that quantity discounts and trade credit do, in fact, influence decisionmaking. However, they did not consider two-part trade credit and lot-splitting shipments, in which the order lot is shipped in equal sub-lot sizes, which is more important in supply chain systems with a powerful retailer.

The aforementioned inventory models implicitly assumed that the retailer does not exert power over suppliers. However, recent studies have demonstrated that retailers have become more powerful than suppliers. Most manufacturers are willing to make concessions because they need to sell their products through a powerful retailer [23,33]. Many suppliers have reported feeling squeezed and pressured by giant retailers into taking expensive actions such as lowering prices, accelerating delivery times, offering special allowances, or carrying extra inventory [2]. In many settings, several coordinating mechanisms (e.g., lot-splitting shipments, trade credit, quantity discounts) between the retailer and supplier are employed to maintain long-term partnerships [32]. Specifically, trade credit and quantity discount mechanisms are significant for supply chain coordination 
through lot-splitting shipments but the literature has not adequately addressed them. This paper therefore formulated a powerful retailer inventory model with quantity discounts and trade credit in which the retailer's order quantity is calculated at one setup and delivered in equal lots over multiple shipments. This trade credit condition involves the retailer making partial cash payments over a given number of sub-shipments with the remaining unpaid balance paid in trade credit time that expires after the inventory is depleted.

This paper makes three contributions. Firstly, to the best of our knowledge, it is the first study that incorporates a specific trade credit condition with quantity discounts factored into a powerful retailer inventory model in which the retailer must make partial cash payment for a given number of sub-shipments with the remaining unpaid balance paid in trade credit time that expires after the inventory is depleted. Secondly, the hybrid coordination mechanisms influencing decision-making are proven according to properties and theorems. Thirdly, an algorithm simplifying the complex solution procedure is provided to enhance decision-making efficiency and a sensitivity analysis provides useful information to examine the effects of the coordination mechanisms.

The remainder of this paper is organized as follows. The model environment notation and assumptions are discussed in Section 2. Section 3 develops a new coordination inventory system with quantity discounts and trade credit under multiple shipments. Section 4 determines the properties and solution processes using an algorithm to calculate the optimal solution. Section 5 presents numerical examples to demonstrate the formulated model and algorithm. Section 6 provides managerial insights and conclusions.

\section{Notation AND ASSUMPtions}

The following notations and assumptions are used throughout this paper to develop the mathematical models.

\section{Notations}

$D$ the demand rate.

$K$ the setup cost for each order.

$M$ permissible delay in settling accounts, $M>T$.

$N$ the number of deliveries for each cycle (integer value), $N \geq z$.

$R$ the receiving cost for each delivery.

$T$ time interval between successive orders.

$q$ order size.

$r$ holding cost rate for a unit per period, expressed as a fraction of dollar value.

$v$ unit selling price per item $\left(v \geq c_{j}\right)$.

$z$ the number of $z$ th shipment (integer value), $z \in\{1,2, \ldots, N\}$.

$I_{e}$ interest rate per $\$$ per year.

$I_{k}$ opportunity cost (or interest charged) per $\$$ in stocks per year and, in practice.

$c_{j}$ the unit-purchasing price of $j$ th level.

$q_{s}$ the size of delivery per shipment in which $q_{s}=q / N$.

$t_{s}$ the inventory depletion time per delivery.

$\alpha$ percent of purchase cost paid in the $z$ th shipment, $0<\alpha<1$.

$\operatorname{TRC}_{j}(T, N)$ the total relevant cost per cycle where $j=1,2, \ldots, r$.

\section{Assumptions}

(1) The demand rate for items is known and constant.

(2) Shortages are not allowed.

(3) The period is infinite and replenishments are instantaneous.

(4) The ordering quantity is determined for each setup and the shipment is a fixed quantity and delivered at regular intervals.

(5) The all-unit quantity discount scheme is employed where $c_{j}$ is the unit-purchasing cost for the $j$ th interval and $Q_{j-1}$ is the lowest order quantity for the $j$ th interval. This means that when the order quantity is between $\left[Q_{j-1}, Q_{j}\right]$, the unit-purchasing cost is then $c_{j}$, where $c_{j-1}>c_{j}$. 
(6) The retailer requests that the supplier pay part of payment $(\alpha)$ in a number of sub-shipments $(z)$ and the retailer employs cash on hand to make the partial payment and thus sustains an opportunity cost loss. Furthermore, the remaining unpaid balance must be paid within the permissible time $(M)$, which expires after the inventory is depleted. Because $0<\alpha<1$, cycle time $T$ is less than $M$ and thus we assume $M-T \geq 0.01$ (year). This interval is the operating period for the remaining payment.

(7) The retailer sells items by each sub-lot and immediately deposits the generated sales revenue into an interest-bearing account.

\section{Model DeVElopment}

In a coordinating a supply chain system, to achieve economic scale and best use resources, suppliers often use quantity discounts and/or trade credit to attract retailers ordering larger quantities. Alternatively, to avoid being exposed to financial risk, suppliers request retailers pay part of the payments in a given time and the rest of the payments at another given time. This paper considers a powerful retailer that has authority over its supplier, using the following coordinating mechanisms to maintain their long-term cooperative relationship. The supplier provides quantity discounts to stimulate the retailer to order larger quantities. He or she also allows the retailer to make payments with trade credit. The trade credit condition is that the retailer must make partial cash payments over a given number of sub-shipments with the remaining unpaid balance paid in trade credit time that expires after the inventory is depleted. The retailer employs his or her cash on hand to make the partial payment and thus bears an opportunity cost. Meanwhile, the retailer requests that its supplier deliver his or her order using lot-splitting shipments. He or she then sells the items and immediately deposits the generated sales revenue into an interest-bearing account at the end of each sub-lot. The chemical industry offers an excellent example of this model environment in agreement with Krichen et al.'s [16] work.

As illustrated in the model environment described above, Figure 1 indicates the inventory system and interestbearing account behaviors for sales revenue. In the top half of Figure 1, the powerful retailer orders lot size $q$ units per cycle and requests that the supplier deliver these quantities in split lots with equal $q_{s}$ units per shipment. This implies the ordered quantity $q$ is delivered $N$ times in equal sub-quantities $q_{s}$ in each cycle (i.e., $\left.q=N q_{s}=D T\right)$. The inventory depletion time per shipment at $q_{s}$ quantities is $t_{s}$, in which the cycle time is $T$ and $T=N t_{s}$. The retailer is asked by the supplier to make part of the payments within time $z * t_{s}$ and the make the remaining payment within time $M$. From the bottom half of Figure 1, corresponding to the top half of Figure 1, we know that the retailer sells items in each sub-lot and immediately deposits the generated sales revenue into an interest-bearing account. The interest earned rate per cycle is from the capital invested after each lot-splitting inventory is depleted until due date $M$. For example, during the first sub-period $t_{s}$, the retailer deposits its sales revenue, $v * q_{s}$, into an interest-bearing account until due date $M$ and thus earns interest $I_{e} * v * q_{s} *\left(M-t_{s}\right)$. In the same way, during the $i$ th sub-period, the interest earned is $I_{e} * v * q_{s} *\left(M-I * t_{s}\right)$, in which $\left(M-i * t_{s}\right) \geq 0$. Thus, the interest earned per unit of time during the permissible settlement period accumulates all interest generated from each sub-period over the entire cycle time. We have:

$$
\begin{aligned}
I E & =\frac{v I_{e}}{T}\left[q_{s}\left(M-t_{s}\right)+q_{s}\left(M-2 t_{s}\right)+\ldots+q_{s}\left(M-N t_{s}\right)\right] \\
& =D v I_{e}\left[M-\left(\frac{T(N+1)}{2 N}\right)\right],
\end{aligned}
$$

where $T=N t_{s}, q=N q_{s}=D T$.

Alternatively, referring to the top half of Figure 1, the retailer makes a part of the payments (say, $\alpha$ ) in cash at time $(z-1) * t_{s}$. The retailer therefore occurs an opportunity cost from $(z-1) * t_{s}$ until due date $M$, in which the opportunity cost per dollar in stocks per year is $I_{k}$. the opportunity cost per unit of time can then 


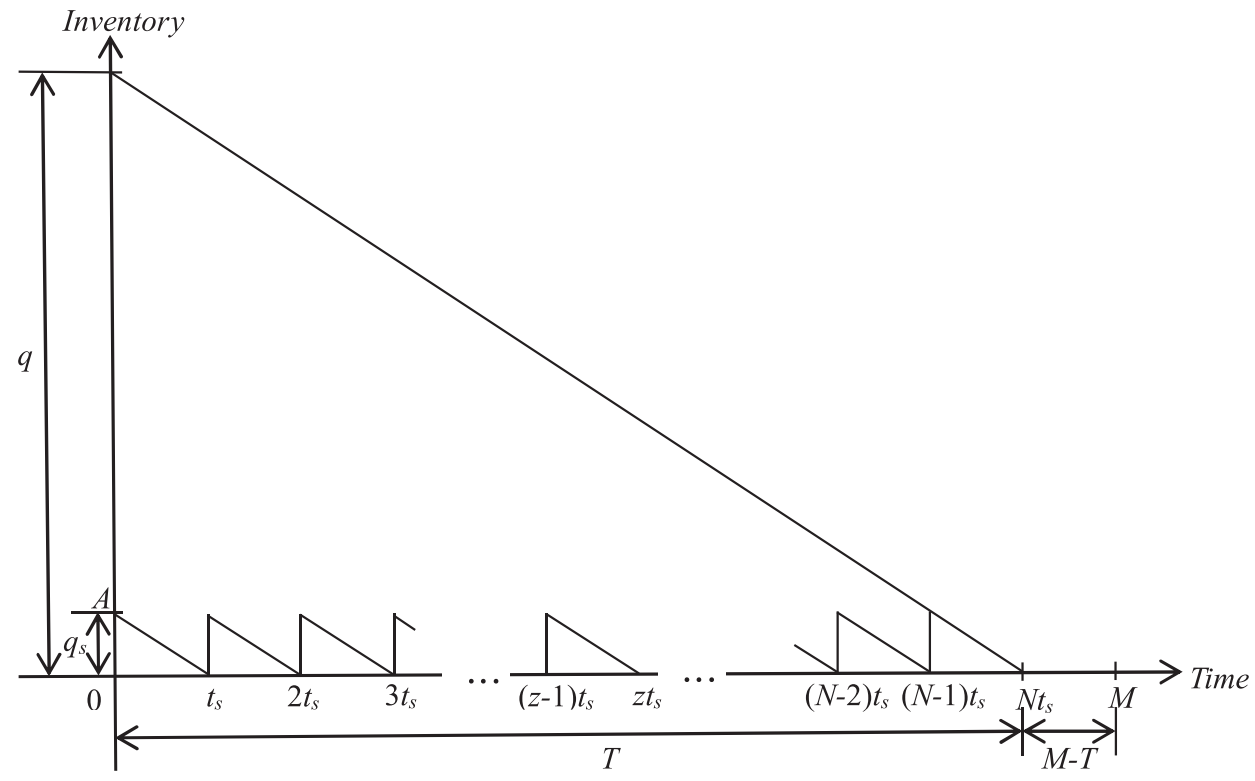

(a)

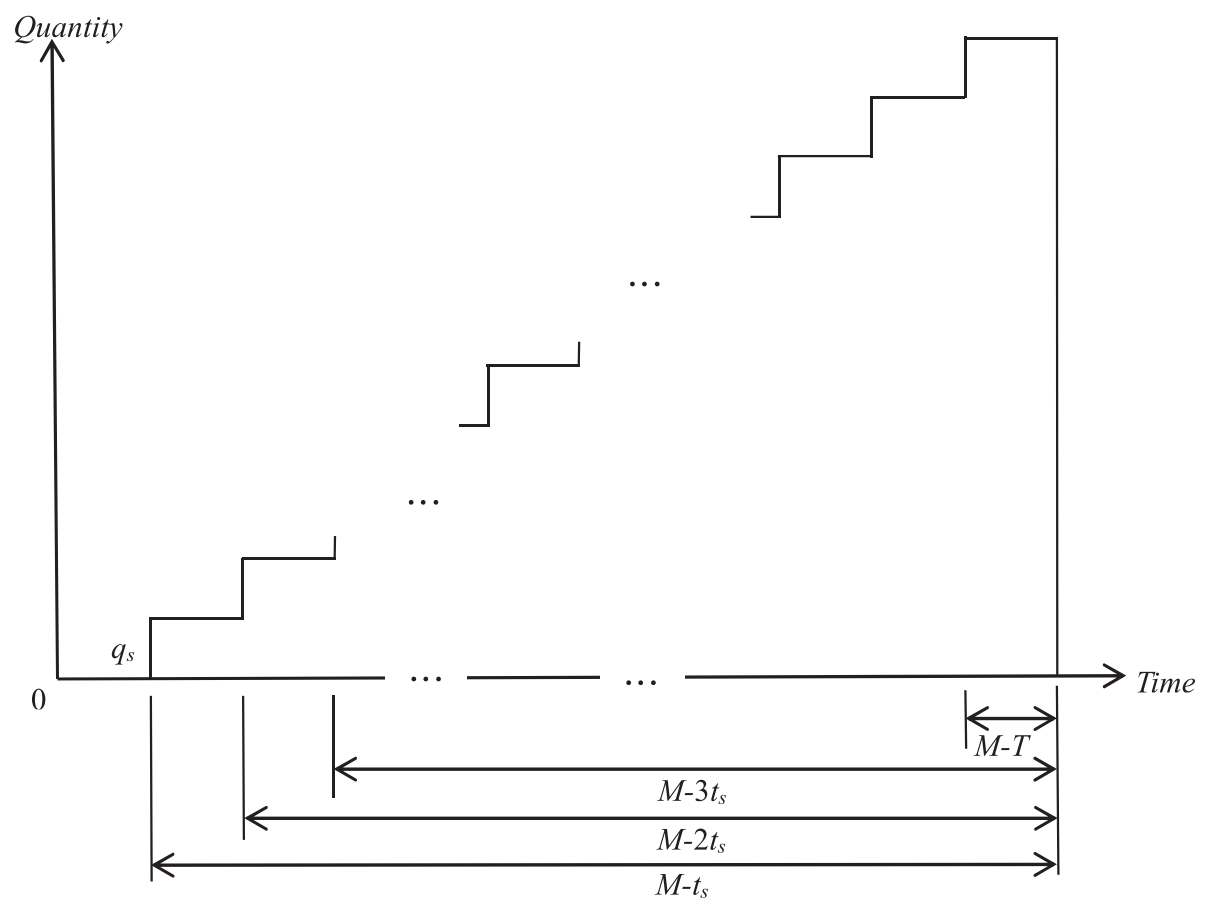

(b)

FigURE 1. Behaviors of inventory system and interest-bearing account for the sales revenue. (a) Behavior of inventory system for permissible delay in payment. (b) Behavior of interestbearing account for the sales revenue. 
be calculated as follows:

$$
\begin{aligned}
O C & =\frac{c_{j} q \alpha I_{k}}{T}\left[M-(z-1) t_{s}\right] \\
& =c_{j} \alpha D I_{k}[M-(z-1) T / N] .
\end{aligned}
$$

The ordering cost per unit of time is $K / T$. The receiving cost per unit of time for each order with $N$ times receiving procedure is $N * R / T$. According to Assumption (4.2), we know if the order quantity is between $\left[Q_{j-1}, Q_{j}\right]$, then the unit-purchasing cost is $c_{j}$. We then obtain the purchasing cost per unit of time as $c_{j} q / T$. The stock holding cost (excluding interest charges) is the unit-purchasing per unit of time, $c_{j} * r$, multiplied by $N$ triangles of the same area $A O t_{s}$ as shown in the top half of Figure 1. Consequently, the holding cost per unit of time is $c_{j} r D T /(2 N)$.

Combing the above results, we obtain the total relevant cost per unit of time as follows:

$$
\begin{aligned}
\text { Total cost }= & \text { Ordering cost }+ \text { Receiving cost }+ \text { Holding cost }+ \text { Opportunity cost }- \text { Interest earned } \\
& + \text { Purchas amount cost } .
\end{aligned}
$$

We then obtain the total relevant cost per year using a mathematical model expressed as follows:

$$
\begin{gathered}
\operatorname{TRC}_{j}(T, N)=\frac{K+N R}{T}+\frac{c_{j} r D T}{2 N}+c_{j} \alpha D I_{k}[M-(z-1) T / N]-D v I_{e}\left[M-\left(\frac{T(N+1)}{2 N}\right)\right]+c_{j} D, \\
j=1,2, \ldots, r .
\end{gathered}
$$

The goal of the objective function is to simultaneously determine the replenishment time and the number of shipments that minimizes the relevant total cost in equation (3.3). However, the supplier offers quantity discounts to the retailer according to its order quantity, which does not meet the type of decision variable in equation (3.3). We therefore skillfully transfer the type of discount by the "quantity" in Assumption (4.2) into the type of discount by "time" using $q=D T$. Furthermore, Assumption (4.3) indicates that permissible delay $M$ is longer than cycle time $T$, and thus $T-M \geq 0$. We therefore have a new discount scheme based on the ordered quantity depleted time as $\left[T_{j-1}, T_{j}\right]$, corresponding to $c_{j}$ in which $T_{r}=(M-0.01)$ and $T_{j}=q_{j} / D$. We note it is hard to confirm the convexity of equation (3.3) because two decision variables need to be simultaneously

determined under the quantity discount scheme. Therefore, the theme results and solution procedure will be developed to find the optimal number of shipments and replenishment time that corresponds to unit-purchasing cost.

\section{ThEOREM RESUlts AND SOLUTION PROCEDURE}

We need the following property to derive the optimal solution for total cost $\operatorname{TRC}_{j}(T, N)$ corresponding to unit-purchasing cost.

Property 4.1. For a fixed $N, \operatorname{TRC}_{j}(T, N)$ is convex to $T$ when $T>0$.

Proof. We let $N$ be fixed in equation (4.4) and then take the derivative of equation (3.3) with respect to $T$ leads to:

$$
\frac{\mathrm{dTRC}_{j}(T, N)}{\mathrm{d} T}=\frac{-(K+N R)}{T^{2}}+\frac{\omega_{j}(N)}{2}, \quad j=1,2, \ldots, r .
$$

where $\omega_{j}(N)=D\left[\frac{c_{j} r+v I_{e}-2 \alpha c_{j} I_{k}(z-1)}{N}+v I_{e}\right] \frac{\mathrm{dTRC}_{j}^{2}(T, N)}{\mathrm{d} T}=\frac{-2(K+N R)}{T^{3}}<0$, if $T>0$ for $j=1,2, \ldots, r$.

Because the cycle time is a positive value, we know that $\operatorname{TRC}_{j}(T, N)$ is convex to $T$ when $N$ is fixed. This completes the proof. 
From Property 4.1, we know a unique solution minimizing equation (3.3) exists. We therefore set $\frac{\operatorname{dTRC}_{j}(T, N)}{\mathrm{d} T}=$ 0 and let its result as be $T_{j}^{\Delta}$. One has:

$$
T_{j}^{\Delta}=\sqrt{\frac{2(K+N R)}{\omega_{j}(N)}}, j=1,2, \ldots, r .
$$

However, the optimal cycle time must be less than or equal to the permissible delay. This implies that the following theorem holds.

Property 4.2. The possible optimal cycle time may occur if $N_{j}^{\mathrm{Low}} \leq N_{j} \leq N_{j}^{\mathrm{Upper}}$, where

$$
N_{j}^{\mathrm{Low}}=\max \left\{z,\left\lceil\frac{-\left(2 K-M^{2} v I_{e} D\right)}{4 R}-\sqrt{\frac{\left(2 K-M^{2} v I_{e} D\right)^{2}+8 R M^{2} D\left(c_{j} r+v I_{e}-2 \alpha c_{j} I_{k}(z-1)\right)}{16 R^{2}}}\right\rceil\right\}
$$

and

$$
N_{j}^{\mathrm{Upper}}=\max \left\{z,\left\lfloor\frac{-\left(2 K-M^{2} v I_{e} D\right)}{4 R}+\sqrt{\frac{\left(2 K-M^{2} v I_{e} D\right)^{2}+8 R M^{2} D\left(c_{j} r+v I_{e}-2 \alpha c_{j} I_{k}(z-1)\right)}{16 R^{2}}}\right\rfloor\right\} .
$$

Proof. See Appendix A.

Substituting equation (4.2) into equation (3.3) and rearranging the formulate yields:

$$
\begin{gathered}
\operatorname{TRC}_{j}(N)=D\left(c_{j}-v I_{e} M+\alpha c_{j} I_{k} M\right)+\sqrt{\frac{2 D(K+N R)\left[c_{j} r+v I_{e}-2 \alpha c_{j} I_{k}(z-1)+N v I_{e}\right]}{N}}, \\
j=1,2, \ldots, r .
\end{gathered}
$$

We ignore the constant terms in equation (4.3) and thus obtain:

$$
\begin{gathered}
\gamma_{j}(N)=2 D\left\{\frac{K}{N}\left[c_{j} r+v I_{e}-2 \alpha c_{j} I_{k}(z-1)\right]+K v I_{e}+R\left[c_{j} r+v I_{e}-2 \alpha c_{j} I_{k}(z-1)\right]+N R v I_{e}\right\}, \\
j=1,2, \ldots, r .
\end{gathered}
$$

Note that minimizing $\operatorname{TRC}_{j}(N)$ is equivalent to minimizing equation (4.4). If we let $N$ be a continuous variable and take the derivative of equation (4.4) with respect to $N$, we obtain:

$$
\frac{\mathrm{d} \gamma_{j}(N)}{\mathrm{d} N}=2 D\left\{-\frac{K\left[c_{j} r+v I_{e}-2 \alpha c_{j} I_{k}(z-1)\right]}{N^{2}}+R v I_{e}\right\}, \quad j=1,2, \ldots, r .
$$

We further take the derivative of $\omega_{j}(N)$ with respect to $N$ and have:

$$
\frac{\mathrm{d} \omega_{j}(N)}{\mathrm{d} N}=\frac{-D\left[c_{j} r+v I_{e}-2 \alpha c_{j} I_{k}(z-1)\right]}{N^{2}}, \quad j=1,2, \ldots, r .
$$

Observing equation (4.10), two cases occur:

Case A: $Y_{j}=\left[c_{j} r+v I_{e}-2 \alpha c_{j} I_{k}(z-1)\right] \geq 0, \quad j=1,2, \ldots, r$.

In this case, we know

$$
\omega_{j}(1)>\lim _{N \rightarrow \infty} \omega_{j}(N)=v I_{e}>0 .
$$


Let

$$
\Omega_{j}=\sqrt{\frac{K\left[c_{j} r+v I_{e}-2 \alpha c_{j} I_{k}(z-1)\right]}{R v I_{e}}}, \quad j=1,2, \ldots, r .
$$

One has

$$
\frac{\mathrm{d} \gamma_{j}(N)}{\mathrm{d} N}\left\{\begin{array}{ll}
<0, & \text { if } 0<N<\Omega_{j} \\
=0, & \text { if } N=\Omega_{j} \\
>0, & \text { if } N>\Omega_{j}
\end{array} \quad, \quad j=1,2, \ldots, r\right.
$$

equation (4.8) indicate that Property 4.3 exists.

Property 4.3. $\gamma_{j}(N)$ is decreasing on $\left(0, \Omega_{j}\right]$ and increasing on $\left[\Omega_{j}, \infty\right)$, where $j=1,2, \ldots, r$.

Because $N$ is a positive integer, the candidate optimal value $N_{j}^{\Delta}$ is obtained when:

$$
\gamma\left(N_{j}^{\Delta}\right) \leq \gamma\left(N_{j}^{\Delta}-1\right) \quad \text { and } \quad \gamma\left(N_{j}^{\Delta}\right) \leq \gamma\left(N_{j}^{\Delta}+1\right) .
$$

From equations (4.5) and (4.9), $N_{j}^{\Delta}$ satisfies the following condition:

$$
\left(N_{j}^{\Delta}-1\right) N_{j}^{\Delta} \leq \frac{K\left[c_{j} r+v I_{e}-2 \alpha c_{j} I_{k}(z-1)\right]}{R v I_{e}} \leq N_{j}^{\Delta}\left(N_{j}^{\Delta}+1\right) .
$$

We plug $N_{j}^{\Delta}$ obtained from equation (4.10) into equation (4.2) to find $T_{j}^{\Delta}\left(N_{j}^{\Delta}\right)$ corresponds to the unitpurchasing cost $c_{j}$, where $T_{j}^{\Delta}\left(N_{j}^{\Delta}\right)$ is valid when $T_{j-1} \leq T_{j}^{\Delta}\left(N_{j}^{\Delta}\right)<T_{j}$ exists. That is, the candidate optimal solution may occur at $\left(T_{j}^{\Delta}\left(N_{j}^{\Delta}\right), N_{j}^{\Delta}\right)$. Otherwise, if $T_{j}^{\Delta}\left(N_{j}^{\Delta}\right)$ is invalid, corresponding to $c_{j}$, two scenarios occur:

Scenario I: $T_{j}^{\Delta}\left(N_{j}^{\Delta}\right)>T_{j}$, where $T_{j}$ is the maximum cycle time corresponding to $c_{j}$.

This scenario implies that the retailer could use the lower unit-purchasing cost (say $c_{k}$, for $c_{k}<c_{j}$ ) to achieve the cycle time $T_{k}^{\Delta}\left(N_{k}^{\Delta}\right)$ in which $\operatorname{TRC}_{k}\left(N_{k}^{\Delta}\right)<\mathrm{TRC}_{j}\left(N_{j}^{\Delta}\right)$. This result indicates that the possible candidate cycle time under $c_{j}$ should not be optimal and we do not further process it.

Scenario II: $T_{j}^{\Delta}\left(N_{j}^{\Delta}\right)<T_{j-1}$, where $T_{j-1}$ is the minimal cycle time corresponding to $c_{j}$.

This scenario has two situations:

Situation 1: The perspective of breakpoint $T_{j-1}$ corresponds to $c_{j}$.

This situation implies that the candidate optimal cycle time could occur at the break point $T_{j-1}$. Therefore, the candidate integer number of shipments under a given $c_{j}$ can be obtained as follows:

$$
\left(\tilde{N}_{j}-1\right) \tilde{N}_{j} \leq \frac{\left(T_{j-1}\right)^{2} D\left[c_{j} r+v I_{e}-2 \alpha c_{j} I_{k}(z-1)\right]}{2 R} \leq \widetilde{N}_{j}\left(\widetilde{N}_{j}+1\right)
$$

If $\widetilde{N}_{j} \geq z$, the candidate optimal solution may occur at $\left(T_{j-1}, \widetilde{N}_{j}\right)$.

Situation 2: The perspective of $N$ corresponds to $c_{j}$.

For a given reasonable $N$, the candidate optimal solution may occur at $\left(T_{j}^{\Delta}\left(N_{j}\right), N_{j}\right)$ in which the condition $T_{j-1} \leq T_{j}^{\Delta}\left(N_{j}\right)<T_{j}$ is satisfied. Therefore, plugging equation (4.6) into $T_{j-1} \leq T_{j}^{\Delta}\left(N_{j}\right)$ we have:

$$
\phi N^{2}+\eta_{j} N-\chi_{j}>0
$$

where $\phi=2 R, \eta_{j}=2 K-D\left(T_{j-1}\right)^{2} v I_{e}$, and

$$
\chi_{j}=\left\{D\left(T_{j-1}\right)^{2}\left[c_{j} r+v I_{e}-2 \alpha c_{j} I_{k}(z-1)\right]\right\} .
$$


We solve the above inequality for $N$ and have:

$$
N_{j}>\frac{-\eta_{j}+\sqrt{\eta_{j}^{2}+4 \phi \chi_{j}}}{2 \phi} \equiv \bar{N}_{j}, \quad j=1,2, \ldots, r .
$$

Let

$$
N_{j}^{\#}=\max \left\{N_{j}^{\text {Low }},\left\lfloor\bar{N}_{j}\right\rfloor\right\}, \quad j=1,2, \ldots, r
$$

where $\left\lfloor\bar{N}_{j}\right\rfloor$ is the smallest integer larger than $\bar{N}_{j}$.

One has $T_{j}^{\Delta}\left(N_{j}^{\#}\right)$ from equation (4.2). Thus, the candidate optimal solution may occur at $\left(T_{j}^{\Delta}\left(N_{j}^{\#}\right), N_{j}^{\#}\right)$. Note that if $T_{j}^{\Delta}\left(N_{j}^{\#}\right)>T_{j}$, we do not further process it because no feasible solution
occurs.

Case B: $Y_{j}=\left[c_{j} r+v I_{e}-2 \alpha c_{j} I_{k}(z-1)\right]<0, \quad j=1,2, \ldots, r$.

In this case, we know that $\left[\mathrm{d} \gamma_{j}(N) / \mathrm{d} N\right]>0$ from equation (4.5). This implies that $\gamma_{j}(N)$ is increasing on $[1, \infty)$. Furthermore, from equation $(4.6)$, one has:

$$
\left[\mathrm{d} \omega_{j}(N) / \mathrm{d} N\right]>0 .
$$

Equation (4.14) implies the following property exists.

Property 4.4. $\omega_{j}(N)$ is increasing on $[1, \infty)$.

Property 4.4 illustrates:

$$
\omega_{j}(N)>\omega_{j}(1) .
$$

Two scenarios occur for $\omega_{j}(N)$, in this case:

Scenario A: $G_{j}=\left[\frac{c_{j} r+v I_{e}-2 \alpha c_{j} I_{k}(z-1)}{N}+v I_{e}\right]>0$.

In this scenario,

$$
N>\frac{-\left[c_{j} r+v I_{e}-2 \alpha c_{j} I_{k}(z-1)\right]}{v I_{e}}=\left\lfloor N_{\min }\right\rfloor
$$

Let

$$
N_{j}^{@}=\left\lfloor N_{\min }\right\rfloor,
$$

where $\lfloor\pi\rfloor$ is the smallest integer larger than $\pi$ and $j=1,2, \ldots, r$.

Because $\omega_{j}\left(N_{j}^{@}\right)>0$, Properties 4.2 and 4.4 exist, and $z \leq N$, the candidate optimal number of shipments is given as follows:

$$
N_{j}^{\S}=\max \left(N_{j}^{@}, N_{j}^{\mathrm{Low}}\right) .
$$

Therefore, the candidate optimal solution may occur at $\left(T_{j}^{\Delta}\left(N_{j}^{\$}\right), N_{j}^{\$}\right)$ in which $T_{j}^{\Delta}\left(N_{j}^{\$}\right)$ is determined by equation (4.2).

However, the candidate optimal cycle time may occur at the break point. Using Property 4.4, we know that the candidate optimal solution may occur at $\left(T_{j-1}, z\right)$ and $(M-0.01, z)$, corresponding to $c_{j}$.

Scenario B: $G_{j}=\left[\frac{c_{j} r+v I_{e}-2 \alpha c_{j} I_{k}(z-1)}{N}+v I_{e}\right] \leq 0$.

In this scenario,

$$
N \leq \frac{-\left[c_{j} r+v I_{e}-2 \alpha c_{j} I_{k}(z-1)\right]}{v I_{e}}=N_{\min }
$$


Two situations occur:

Situation A: $z=1$.

In this situation, equation (4.18) illustrates that no optimal number of shipments may occur. We therefore do not process it further.

Situation B: $z \geq 2$.

In this situation,

$$
N \leq \frac{-\left[c_{j} r+v I_{e}-2 \alpha c_{j} I_{k}(z-1)\right]}{v I_{e}} .
$$

Because $z \leq N$ and equation (4.15) holds, we know that the candidate optimal number of shipments is $z$. The candidate optimal solution may occur at $\left(T_{j}^{\Delta}(z), z\right)$ in which $T_{j}^{\Delta}(z)$ is determined by equation (4.2). However, the candidate optimal cycle time might also occur at the break point. Using Property 4.4, we know that the candidate optimal solution may occur at $\left(T_{j-1}, z\right)$ and $(M-0.01, z)$ corresponding to $c_{j}$.

Based on the above analysis we have the following results:

Theorem: The candidate optimal solution $(T, N)$ can be determined as follows:

(1) If $Y_{j} \geq 0$, three possible candidate optimal solution sets occur, as detailed below:

(a) If $N_{j}^{\text {Low }} \leq N_{j}^{\Delta} \leq N_{j}^{\text {Upper }}$, where $N_{j}^{\Delta}$ obtained from equation (4.10), the possible candidate optimal solution, may occur at $\left(T_{j}^{\Delta}\left(N_{j}^{\Delta}\right), N_{j}^{\Delta}\right)$, where $T_{j}^{\Delta}\left(N_{j}^{\Delta}\right)$ obtained from equation (4.2) and $T_{j-1} \leq T_{j}^{\Delta}\left(N_{j}^{\Delta}\right)<T_{j}$.

(b) If $N_{j}^{\text {Low }} \leq \widetilde{N}_{j} \leq N_{j}^{\text {Upper }}$, where $\widetilde{N}_{j}$ obtained from equation (4.11) and $T_{j-1}$ is the break point corresponding to $c_{j}$.

(c) If $N_{j}^{\text {Low }} \leq N_{j}^{\#} \leq N_{j}^{\text {Upper }}$, where $N_{j}^{\#}$ obtained from equation (4.13), the possible candidate optimal solution, occurs at $\left(T_{j}^{\Delta}\left(N_{j}^{\#}\right), N_{j}^{\#}\right)$, where $T_{j}^{\Delta}\left(N_{j}^{\#}\right)$ is obtained from equation (4.2).

(2) If $Y_{j}<0$ three possible candidate optimal solution sets occur as below:

(a) If $G_{j}>0$ and $N_{j}^{\text {Low }} \leq N_{j}^{\$} \leq N_{j}^{\text {Upper }}$ where $N_{j}^{\$}$ obtained from equation (4.17), the candidate optimal solution, may occur at $\left(T_{j}^{\Delta}\left(N_{j}^{\$}\right), N_{j}^{\$}\right)$, where $T_{j}^{\Delta}\left(N_{j}^{\$}\right)$ obtained from equation (4.2).

(b) If $G_{j}>0$, the candidate optimal solution may occur at $\left(T_{j-1}, z\right)$ or $(M-0.01, z)$.

(c) If $G_{j} \leq 0$ and $z \geq 2$, the candidate optimal solution may occur at $\left(T_{j}^{\Delta}(z), z\right)$, and $T_{j}^{\Delta}(z)$ determined by equation $(4.2),\left(T_{j-1}, z\right)$, or $(M-0.01, z)$.

We note that if the retailer employs a single shipment, which means $N=1$ and $z=1$, then equation (3.3) reduces as follows:

$$
\operatorname{TRC}_{j}(T)=\frac{K+R}{T}+\frac{c_{j} r D T}{2}+c_{j} \alpha D I_{k} M-D v I_{e}[M-T]+c_{j} D, \quad j=1,2, \ldots, r .
$$

We therefore derive equation (4.20) and set it to zero. One has the replenishment time at $N=1$ as follows:

$$
T_{j}^{1}=\sqrt{\frac{2(K+N R)}{c_{j} r D+2 D v I_{e}}}, \quad j=1,2, \ldots, r .
$$

Comparing equations (4.2) and (4.21), we know that the replenishment time for multiple shipments is longer than that for individual ones.

Until now, we could not obtain the overall optimal solution but obtained the candidate optimal lot cycle time and the number of shipments. We therefore developed Algorithm 4.5 to calculate the overall optimal cycle time and number of shipments. 
Algorithm 4.5. Step 1. Compute $Y_{j}$, where $j=1,2, \ldots, r$ and $Y_{j}=\left[c_{j} r+v I_{e}-2 \alpha c_{j} I_{k}(z-1)\right]$.

Step 2. For $j=1$ to $r$

$\left\{\right.$ Compute $N_{j}^{\text {Low }}$ and $N_{j}^{\text {Upper }}$ from Property 4.2$\}$

If $Y_{j} \geq 0$, Do \{

\{Compute $N_{j}^{\Delta}$ from equation (4.10)\}

If $N_{j}^{\text {Low }} \leq N_{j}^{\Delta} \leq N_{j}^{\text {Upper }}$, Do \{

\{Compute $T_{j}^{\Delta}\left(N_{j}^{\Delta}\right)$ from equation (4.2)\}

If $T_{j-1} \leq T_{j}^{\Delta}\left(N_{j}^{\Delta}\right)<T_{j}$, Do \{

\}

$\left\{\right.$ Compute $\mathrm{TRC}_{j}\left(T_{j}^{\Delta}\left(N_{j}^{\Delta}\right), N_{j}^{\Delta}\right)$ from equation (3.3) and record it\}

Else

$\left\{\operatorname{Record} \operatorname{TRC}_{j}\left(T_{j}^{\Delta}\left(N_{j}^{\Delta}\right), N_{j}^{\Delta}\right)=\infty\right\}$

\{Obtain $T_{j-1}$ corresponding to $c_{j}$ from Table 1 and compute $\widetilde{N}_{j}$ obtained from equation (4.11)\} If $\widetilde{N}_{j} \geq z$, Do \{

$\left\{\right.$ Compute $\mathrm{TRC}_{j}\left(T_{j-1}, \widetilde{N}_{j}\right)$ from equation (3.3) and record it\}

\}

Else

$\left\{\operatorname{Record} \operatorname{TRC}_{j}\left(T_{j-1}, \widetilde{N}_{j}\right)=\infty\right\}$

\{Compute $N_{j}^{\#}$ from equation (4.13)\}

If $N_{j}^{\text {Low }} \leq N_{j}^{\#} \leq N_{j}^{\text {Upper }}$, Do \{

$\left\{\right.$ Compute $T_{j}^{\Delta}\left(N_{j}^{\#}\right)$ from equation (4.2)\}

If $T_{j-1} \leq T_{j}^{\Delta}\left(N_{j}^{\#}\right)<T_{j}$, Do \{

$\left\{\right.$ Compute $\mathrm{TRC}_{j}\left(T_{j}^{\Delta}\left(N_{j}^{\#}\right), N_{j}^{\#}\right)$ from equation (3.3) and record it\}

\}

\}

Else

Next $j$

$\left\{\operatorname{Record} \operatorname{TRC}_{j}\left(T_{j}^{\Delta}\left(N_{j}^{\#}\right), N_{j}^{\#}\right)=\infty\right\}$

\}

If $Y_{j}<0$, Do \{

$\left\{\right.$ Compute $\operatorname{TRC}_{j}\left(T_{j-1}, z\right)$ and $\left.\operatorname{TRC}_{r}(M-0.01, z)\right\}$

\{Compute $N_{j}^{\$}$ from equation (20)\}

If $N_{j}^{\text {Low }} \leq N_{j}^{\$} \leq N_{j}^{\text {Upper }}$, Do \{

$\left\{\right.$ Compute $G_{j}$, where $\left.G_{j}=\frac{-\left(c_{j} r+v I_{e}-2 \alpha c_{j} I_{k}(z-1)\right)}{N_{i}^{\S}}\right\}$

If $G_{j}>0$, Do \{

\{Compute $T_{j}^{\Delta}\left(N_{j}^{\$}\right)$ from equation (4.2)\}

If $T_{j-1} \leq T_{j}^{\Delta}\left(N_{j}^{\$}\right)<T_{j}$, Do \{

\{Compute $\operatorname{TRC}_{j}\left(T_{j}^{\Delta}\left(N_{j}^{\$}\right), N_{j}^{\$}\right)$ from equation (3.3) and record it\}

\}

Next $j$

\}

If $G_{j} \leq 0$, Do \{

If $z \geq 2$, Do \{ 
$\left\{\right.$ Compute $\mathrm{TRC}_{j}\left(T_{j-1}, z\right)$ and $\left.\mathrm{TRC}_{r}(M-0.01, z)\right\}$

\{Compute $T_{j}^{\Delta}(z)$ from equation (4.2)\}

If $T_{j-1} \leq T_{j}^{\Delta}\left(N_{j}^{\Delta}\right)<T_{j}$, Do \{

If $T_{j}^{\Delta}(z) \leq M$, Do \{

\{Compute $\mathrm{TRC}_{j}\left(T_{j}^{\Delta}(z), z\right)$ from equation (3.3) and record it\}

\}

Next $j$

\}

\}

Else

Do \{

$\left\{\operatorname{Record} \operatorname{TRC}_{j}\left(T_{j}^{\Delta}(1), 1\right)=\infty\right\}$

$\{$ Next $j\}$

$$
\}
$$

Else

Do \{

$\left\{\operatorname{Record} \operatorname{TRC}_{j}\left(T_{j}^{\Delta}\left(N_{j}^{\$}\right), N_{j}^{\$}\right)=\infty\right\}$

$\{$ Next $j$ \}

\}

Step 3. For $j=1$ to $r$

$$
\begin{aligned}
& \text { Do }\{ \\
& \left\{\operatorname{TRC}_{j}\left(T_{j}, N_{j}\right)=\min \left\{\operatorname{TRC}_{j}\left(T_{j}^{\Delta}\left(N_{j}^{\Delta}\right), N_{j}^{\Delta}\right), \operatorname{TRC}_{j}\left(T_{j-1}, \tilde{N}_{j}\right), \operatorname{TRC}_{j}\left(T_{j-1}, z\right)\right.\right. \\
& \left.\operatorname{TRC}_{r}(M-0.01, z), \operatorname{TRC}_{j}\left(T_{j}^{\Delta}\left(N_{j}^{\#}\right), N_{j}^{\#}\right), \operatorname{TRC}_{j}\left(T_{j}^{\Delta}\left(N_{j}^{\$}\right), N_{j}^{\$}\right), \operatorname{TRC}_{j}\left(T_{j}^{\Delta}(z), z\right)\right\}
\end{aligned}
$$

$\left\{\operatorname{Record}_{\mathrm{TRC}_{j}}\left(T_{j}, N_{j}\right)\right\}$

Next $j$

\}

Step 4. Compare all $\mathrm{TRC}_{j}\left(T_{j}, N_{j}\right)$ recorded in Step 3. The minimal $\mathrm{TRC}_{j}\left(T_{j}, N_{j}\right)$ is the optimal solution corresponding to unit-purchasing cost $c_{j}$. If all $\operatorname{TRC}_{j}\left(T_{j}, N_{j}\right)=\infty$, no optimal solution exists.

Step 5. Stop.

\section{NUMERICAL EXAMPLES AND SENSITIVITY ANALYSIS}

As indicated in the introduction, a powerful retailer in China's the chemical is considered in this paper. A few examples were taken from estimated data due to trade secrets to demonstrate the above solution procedures. Applying the algorithm developed in Section 4, we can easily and efficiently solve the following examples.

Example 1. $D=3000$ units/year, $K=\$ 100 /$ order, $I_{k}=\$ 0.15 / \$ /$ year, $I_{e}=\$ 0.09 / \$ /$ year, $R=\$ 5 /$ receive, $v=\$ 15 /$ item, and $M=0.35$ year. To maintain long-term cooperation, the retailer and supplier have reached an agreement in which the retailer must pay $10 \%$ (i.e., $\alpha=0.1$ ) of the total purchase cost on the second shipment (i.e., $z=2$ ). The holding cost is $30 \%$ of the unit-purchasing cost (i.e., $r=0.3$ ). The supplier also offers a price discount schedule for the following intervals: $[1,200)$ corresponding to $c_{1}=10.05,[200,400)$ corresponding to $c_{2}=10.04,[400,650)$ corresponding to $c_{3}=10.03,[650,900)$ corresponding to $c_{4}=10.02$ and $[900, \infty)$ corresponding to $c_{5}=10.01$. Because the permissible payment time is 0.35 year and $q=D T$, the above intervals can be easily and tacitly transferred into Table 1. 
TABLE 1. Purchase price discount structure based on duration.

\begin{tabular}{lll}
\hline \hline$j$ & $T_{j-1} \leq T<T_{j}$ & $c_{j}$ \\
\hline 1 & $0<T<0.06667=(200 / 3000)$ & 10.05 \\
2 & $(200 / 3000)=0.06667 \leq T<0.13333=(400 / 3000)$ & 10.04 \\
3 & $(400 / 3000)=0.13333 \leq T<0.216667=(650 / 3000)$ & 10.03 \\
4 & $(650 / 3000)=0.216667 \leq T<0.3=(900 / 3000)$ & 10.02 \\
5 & $(900 / 3000)=0.2 \leq T \leq(0.35-0.01)$ & 10.01 \\
\hline
\end{tabular}

Based on the algorithm formulated in Section 4, we calculate the optimal replenishment time, number of shipments, unit-purchasing cost, and minimum cost as follows (see Appendix B): The optimal replenishment time is 0.223440 year, the optimal number of deliveries is eight, and the unit-purchasing cost is $c_{4}=10.02$. The minimum annual total cost is $\$ 30000.84$.

Example 2. The parameters are the same as those in Example 1 except that $\alpha=0.8$ and $I_{k}=\$ 0.3 / \$ /$ year. Again, employing the algorithm developed in Section 4, we found $Y_{j}<0$ and $G_{j}>0$. One can easily obThursday, 7 November 19, 2020 at 7:03 pmtain the following results: the optimal replenishment time is 0.255518 year, the optimal number of deliveries is two, the unit-purchasing cost is $c_{4}=\$ 10.02$, and the annual total cost is $\$ 32028.53$

A sensitivity analysis was carried out on the proposed model to understand the influence of the model parameters on the optimal strategy. In theory, parameters such as $D, K, r, \alpha, R, v, I_{k}, I_{e}, z$, and $M$ should be explored to realize their effects on optimal policy. However, determining the influence of the above parameters on the optimal strategy is a laborious calculation. We, therefore, employed four significant parameters (i.e., $\left.K, r, I_{e}, R\right)$ according to the authors' experience and the literature to perform a sensitivity analysis. A $2^{k}$ full factorial design was used to find the effects of the four parameters on optimal policy and their interactions. These five parameters are set to two levels (i.e., low and high), expressed as follows: $K=(100,150) ; r=(0.3,0.45)$; $I_{e}=(0.06,0.09)$; and $R=(5,7.5)$. Except for the above four parameters, the other parameters remain unchanged. Table 1 indicates the optimal solution under 16 combinations of $K, r, I_{e}$, and $R$. Some findings are listed in Table 2 and described below.

(1) It is found that TRC* increases with $r$; while by combining $T^{*}$ and $N^{*}$, three cases occur when $r$ increases:

Case I: $T^{*}$ remains unchanged and $N^{*}$ increases with $r$.

Case II: $T^{*}$ and $N^{*}$ both increase with $r$.

Case III: $T^{*}$ decreases as $r$ increase while $N^{*}$ increases with $r$.

Observing Case (I) in this finding, the effect of quantity discounts significantly influences the optimal strategy. This leads to $T^{*}$ remaining unchanged and $N^{*}$ decreasing with $r$. In general, the higher the unit holding cost is, the larger the number of shipments and the total relevant cost, which agrees with the results obtained from conventional inventory models. This illustrates that if the unit holding cost increases, the retailer employs more shipments to reduce its holding cost, in which the effect of the receiving cost does not significantly impact the optimal strategy. However if the interaction effect between unit holding cost and receiving cost significantly exists, Cases (II) and (III) occur.

As to Cases (II) and (III), the optimal replenishment time does not occur at the break point of the quantity discount. This leads to different combinations between $T^{*}$ and $N^{*}$ to achieve the minimal total cost. We note that the replenishment time in traditional inventory models with no receiving cost decreases with the unit holding cost. To our knowledge, the lower the replenishment time, the lower the unit holding cost, which agrees with the result of Case (III) in this finding. This indicates that the receiving cost does not 
TABLE 2. The values of $N^{*}, T^{*}$, and $\mathrm{TRC}^{*}$ corresponding to 16 combinations of $I_{e}, K, r, R$.

\begin{tabular}{llllrlll}
\hline \hline$I_{e}$ & $K$ & $r$ & $R$ & $N^{*}$ & $T^{*}$ & \multicolumn{1}{l}{$c_{j}$} & TRC $^{*}$ \\
\hline \multirow{20.06}{*}{100} & 0.3 & 5 & 10 & 0.3 & 10.01 & 30261.73 \\
& & & 7.5 & 8 & 0.3 & 10.01 & 30336.72 \\
\cline { 3 - 7 } & & 0.45 & 5 & 12 & 0.3 & 10.01 & 30323.6 \\
& & 7.5 & 10 & 0.3 & 10.01 & 30412.63 \\
\cline { 3 - 7 } & 150 & 0.3 & 5 & 11 & 0.33244 & 10.01 & 30423.41 \\
& & 7.5 & 9 & 0.332516 & 10.01 & 30498.31 \\
\cline { 3 - 7 } & & 0.45 & 5 & 13 & 0.332007 & 10.01 & 30485.26 \\
& & 7.5 & 11 & 0.335979 & 10.01 & 30574.12 \\
\hline 0.09 & 100 & 0.3 & 5 & 8 & 0.22344 & 10.02 & 30000.84 \\
& & & 7.5 & 6 & 0.217544 & 10.02 & 30080.77 \\
\cline { 2 - 7 } & 0.45 & 5 & 9 & 0.221027 & 10.02 & 30059.77 \\
& & 7.5 & 7 & 0.217033 & 10.02 & 30153.02 \\
\cline { 2 - 7 } & 150 & 0.3 & 5 & 10 & 0.3 & 10.01 & 30226.7 \\
& & 7.5 & 8 & 0.3 & 10.01 & 30305.29 \\
\cline { 2 - 6 } & 0.45 & 5 & 12 & 0.3 & 10.01 & 30285.94 \\
& & 7.5 & 10 & 0.3 & 10.01 & 30377.6 \\
\hline
\end{tabular}

significantly affect optimal strategy in Case (III). We therefore know that the retailer might simultaneously reduce its number of shipments to achieve the minimal total cost. Thus, $T^{*}$ decreases as $r$ increases while $N^{*}$ increases with $r$. Alternatively, if the effect of a receiving cost being larger than that of the unit holding cost, the retailer extends its replenishment time to reduce the ordering frequency and the annual total cost, which matches the results of Case (II) in this finding.

(2) $\mathrm{TRC}^{*} N^{*}$ and $T^{*}$ all decrease when $I_{e}$ increases. In general, the longer the replenishment time $(T)$ to the due date of the trade credit $(M)$ is, the higher the interest rate. This illustrates that $T^{*}$ decreases with $I_{e}$. At the same time, the number of shipments decreases with $I_{e}$ to enhance the effect of the combination of $N^{*}$ and $T^{*}$, which makes TRC* decrease. We note, although $N^{*}$ and $T^{*}$ decrease with $I_{e}$, their corresponding unit-purchasing cost, $c_{j}$, remains unchanged or increases. If $c_{j}$ increases with $I_{e}$ especially occurring with the low level set up cost scenario, the retailer significantly enjoys the benefit of the quantity discounts. Otherwise, $c_{j}$ remains unchanged. All of these illustrations intuitively indicate that TRC* decreases with $I_{e}$. That is, the retailer employs less replenishment time and a lower number of shipments to obtain the minimum annual total cost, which aligns with the results in Lin's [18] work.

(3) Case I: $T^{*}$ remains unchanged and $N^{*}$ decreases with $R$.

Case I: $T^{*}$ remains unchanged and $N^{*}$ is decreasing with $R$.

Case II: $T^{*}$ and $N^{*}$ both decrease with $R$.

Case III: $T^{*}$ increases as $r$ increases while $N^{*}$ decreases with $R$.

In general, the total cost increases with the unit receiving cost if the replenishment time remains unchanged. It is intuitive that the higher the receiving cost is, the fewer the number of shipments, which agrees with the result of Case (I) in this finding; that is, the retailer reduces the receiving frequency to achieve the minimum total cost when the receiving cost increases. We also note that the optimal replenishment time occurs at the break point of quantity discounts. This illustrates that the quantity discount policy truly impacts the optimal decision-making strategy. However, as with Finding (1) in this section, if the interaction effect between receiving cost and unit holding cost occurs, the replenishment time does not remain unchanged, which is discussed in the following paragraph 
As to Cases (II) and (III) in this finding, quantity discounts do significantly influence the optimal solution, like (1) in the findings above. It is recognized that, in general, the replenishment time increases with the receiving cost; that is, the higher the receiving cost, the larger the replenishment time. If the unit holding cost does not significantly influence the optimal decision-making strategy, the retailer may simultaneously deliver its order with fewer shipments to enhance the minimum total cost, which agrees with Case (III) in this finding. Alternatively, if the interaction effect between the receiving cost and unit holding cost is significant, then Case (II) in this finding occurs. In this case, the holding cost significantly impacts the optimal solution, leading to the replenishment time and the number of shipments decreasing, which agrees with our expectation.

(4) $\operatorname{TRC}^{*} N^{*}$ and $T^{*}$ all increase with $K$. It is intuitive that the higher the setup cost is, the larger the replenishment time, which agrees with the results of traditional EOQ models; that is, the retailer extends the replenishment time to reduce the frequency of ordering and setup, which can decrease the setup cost effect and reduce the total cost. At the same time, the number of shipments simultaneously increases to obtain the minimum total cost. We note, the unit-purchasing cost remains unchanged as the setup cost increases under a low interest rate level. Alternatively, with a high interest rate level, the unit-purchasing cost decreases as the setup cost increases. This illustrates that quantity discounts do influence the optimal strategy corresponding to the unit-purchasing cost, like (2) in the findings above.

\section{Conclusion}

This paper proposed a powerful retailer inventory model in which the retailer exerts power over its supplier and some coordinating mechanisms are agreed upon to maintain their long-term cooperative relationship. We reveal that trade credit and quantity discounts truly do impact a retailer's replenishment time and delivery policy. The integrated mechanism for trade credit and quantity discounts can achieve perfect coordination of the supply chain and a "win-win" result, which agrees with the results in Wang and Liu's [32] work. We also demonstrated that a unique optimal set of replenishment times and number of shipments exist such that the relevant cost per year is minimized. This paper also indicated that the replenishment time for multiple shipments is longer than that of a single shipment. An efficient algorithm was developed to find the optimal solution. This paper further revealed that the optimal number of deliveries occurs at $z$ if $Y_{j}<0$ and $G_{j} \leq 0$. Numerical examples were provided that verify that the developed algorithm is valid and demonstrated the following five points. (i) The minimum total cost for the inventory system might not occur at the minimum unit-purchasing cost because the extra quantity purchased (i.e., the ordering lot size occur at the break point of quantity discounts) adds additional costs and thus increases the annual total cost. (ii) As the interest rate increases, the values for the optimal replenishment time, the number of shipments, and the annual total costs decrease. However, if the effect of the quantity discount is insignificant, the unit-purchasing cost might increase with the interest rate, but only if the effect of the setup cost is significantly larger than that of the interest rate, which leads the optimal replenishment time not to occur at the break point of the ordering quantity. (iii) The higher the unit holding cost rate, the higher the annual total cost and number of shipments. However, the replenishment time might remain unchanged, increase, or decrease, depending on the comprehensive effects of quantity discounts, unit holding costs, and receiving costs. (iv) The higher the setup cost, the larger the replenishment time, number of shipments, and annual total costs are. The unit-purchasing cost remains unchanged as the setup cost increases under a low interest rate. Alternatively, with a high interest rate, the unit-purchasing cost decreases as the setup cost increases. (v) The higher the receiving cost rate, the higher the annual total cost and the fewer the number of shipments becomes. However, as described in (i) above, the replenishment time might remain unchanged, increase, or decrease depending on the comprehensive effects of quantity discounts, unit holding costs, and receiving costs.

The proposed models can be further extended by considering more realistic assumptions, such as probability demand, deteriorating items, finite rate of replenishment and the time value of money. 


\section{Appendix A. Proof of Property 4.2}

From equation (4.2), we have

$$
T_{j}^{\Delta}=\sqrt{\frac{2(K+N R)}{\omega_{j}(N)}} .
$$

Furthermore, from Assumption (4.3), we know the permissible delay in payment is $M$, which is greater than or equal to cycle time. Therefore, we have

$$
\sqrt{\frac{2(K+N R)}{\omega_{j}(N)}} \leq M
$$

Squaring on both sides for the above inequality, we have

$$
2 R N_{j}^{2}+\left(2 K-M^{2} D v I_{e}\right) N_{j}-M^{2} D\left[c_{j} r+v I_{e}-2 \alpha c_{j} I_{k}(z-1)\right] \leq 0 .
$$

This implies

$$
N_{j} \geq \frac{-\left(2 K-M^{2} v I_{e} D\right)}{4 R}-\sqrt{\frac{\left(2 K-M^{2} v I_{e} D\right)^{2}+8 R M^{2} D\left(c_{j} r+v I_{e}-2 \alpha c_{j} I_{k}(z-1)\right)}{16 R^{2}}}
$$

or

$$
N_{j} \leq \frac{-\left(2 K-M^{2} v I_{e} D\right)}{4 R}+\sqrt{\frac{\left(2 K-M^{2} v I_{e} D\right)^{2}+8 R M^{2} D\left(c_{j} r+v I_{e}-2 \alpha c_{j} I_{k}(z-1)\right)}{16 R^{2}}} .
$$

Because $N_{j}$ is a positive integer and $N_{j} \geq z$, we therefore have

$$
N_{j}^{\text {Low }} \leq N_{j} \leq N_{j}^{\text {Upper }},
$$

where

$$
N_{j}^{\text {Low }}=\max \left\{z, \frac{-\left(2 K-M^{2} v I_{e} D\right)^{2}}{4 R}-\sqrt{\frac{\left(2 K-M^{2} v I_{e} D\right)^{2}+8 R M^{2} D\left(c_{j} r+v I_{e}-2 \alpha c_{j} I_{k}(z-1)\right)}{16 R^{2}}}\right\}
$$

and

$$
N_{j}^{\mathrm{Upper}}=\max \left\{z, \frac{-\left(2 K-M^{2} v I_{e} D\right)}{4 R}+\sqrt{\frac{\left(2 K-M^{2} v I_{e} D\right)^{2}+8 R M^{2} D\left(c_{j} r+v I_{e}-2 \alpha c_{j} I_{k}(z-1)\right)}{16 R^{2}}}\right\}
$$

and

$\left\lceil\tau_{j}\right\rceil$ is the smallest integer larger than or equal to $\tau_{j}$;

$\left\lfloor\tau_{j}\right\rfloor$ is the greatest integer less than or equal to $\tau_{j}$.

This completes the proof.

\section{Appendix B. Computational procedure for Example 1}

Step 1. Compute $Y_{j}$ as follows:

$$
Y_{1}=4.164 ; \quad Y_{2}=4.1612 ; \quad Y_{3}=4.1584 ; \quad Y_{4}=4.1556 ; \quad Y_{5}=4.1528 .
$$


Step 2. Compute $N_{j}^{\mathrm{Low}}$ and $N_{j}^{\mathrm{Upper}}$ from Property 4.2 shown as follows:

$$
\begin{array}{ll}
\left(N_{1}^{\text {Low }}=2, N_{1}^{\text {Upper }}=34.100\right), & \left(N_{2}^{\text {Low }}=2, N_{2}^{\text {Upper }}=34.097\right), \\
\left(N_{3}^{\text {Low }}=2, N_{3}^{\text {Upper }}=34.095\right), & \left(N_{4}^{\text {Low }}=2, N_{4}^{\text {Upper }}=34.092\right) \\
\left(N_{5}^{\text {Low }}=2, N_{5}^{\text {Upper }}=34.089\right) . &
\end{array}
$$

Because $Y_{j}>0$ for $j=1,2, \ldots, 5$, compute $N_{j}^{\Delta}$ from equation (4.10) shown as follows:

$$
N_{j}^{\Delta}=8, \quad \text { for } j=1,2, \ldots, 5 .
$$

Because $N_{j}^{\text {Low }} \leq N_{j}^{\Delta} \leq N_{j}^{\text {Upper }}$ for $j=1,2, \ldots, 5$, we compute $T_{j}^{\Delta}\left(N_{j}^{\Delta}\right)$ as follows:

$$
T_{1}^{\Delta}(8)=0.223378, \quad T_{2}^{\Delta}(8)=0.223398, \quad T_{3}^{\Delta}(8)=0.223419, \quad T_{4}^{\Delta}(8)=0.22344, \quad T_{5}^{\Delta}(8)=0.223461 .
$$

We found $T_{4}^{\Delta}(8)=0.22344$ is under the interval $[0.216667,0.3)$ corresponding to $c_{4}$. Thus, we have $\mathrm{TRC}_{4}(0.22344,8)=30000.84$ and record it.

We then compute $\widetilde{N}_{j}$ from equation (4.11) shown as follows:

$$
\tilde{N}_{1}=1, \quad \tilde{N}_{2}=2, \quad \widetilde{N}_{3}=5, \quad \widetilde{N}_{4}=8, \quad \tilde{N}_{5}=11 .
$$

Because $z=2$, we then have the following results and record them:

$$
\begin{gathered}
\mathrm{TRC}_{2}(0.066667,2)=30800.98, \quad \mathrm{TRC}_{3}(0.133333,5)=30151.65, \\
\mathrm{TRC}_{4}(0.2166667,8)=30010.44, \quad \mathrm{TRC}_{5}(0.3,11)=30011.66 .
\end{gathered}
$$

We next compute $N_{j}^{\#}$ from equation (4.13) shown as follows:

$$
N_{1}^{\#}=2, \quad N_{2}^{\#}=2, \quad N_{3}^{\#}=2, \quad N_{4}^{\#}=8, \quad N_{5}^{\#}=22 .
$$

We need to substitute the above values into equation (4.2). Thus, we have

$$
\begin{array}{r}
T_{1}^{\Delta}(2)=0.146176, \quad T_{2}^{\Delta}(2)=0.1462062, \quad T_{3}^{\Delta}(2)=0.146236, \\
T_{4}^{\Delta}(8)=0.22344, \quad T_{5}^{\Delta}(22)=0.301632 .
\end{array}
$$

We not $T_{3}^{\Delta}(2)=0.146232, T_{4}^{\Delta}(8)=0.22344$, and $T_{5}^{\Delta}(22)=0.301632$ are located in the interval of $[0.133333,0.2166667),[0.2166667,0.3),[0.3,0.34]$ respectively. We therefore have

$$
\begin{aligned}
\mathrm{TRC}_{3}(0.146236,2) & =30282.23 \\
\mathrm{TRC}_{4}(0.223340,8) & =30000.84 \\
\mathrm{TRC}_{5}(0.301632,22) & =30110.03 .
\end{aligned}
$$

Step 3. $\mathrm{TRC}_{2}\left(T_{2}, N_{2}\right)=\mathrm{TRC}_{2}(0.066667,2)=30800.98$,

$$
\begin{gathered}
\mathrm{TRC}_{3}\left(T_{3}, N_{3}\right)=\min \{30282.23,30151.65\} \\
\operatorname{TRC}_{4}\left(T_{4}, N_{4}\right)=\min \{30000.84,300010.44\} .
\end{gathered}
$$

Step 4. Comparing all $\mathrm{TRC}_{j}\left(T_{j}, N_{j}\right)$ recorded in Step 3, the minimum annual total cost is $\$ 30000.84$. Therefore, the optimal replenishment time is 0.22344 year, the optimal number of shipments is 8 times, and the unit-purchasing cost is $c_{4}=10.02$.

Step 5. Stop.

Acknowledgements. The authors sincerely thank the anonymous referees for their very helpful comments and for the improvement of the paper. This research was supported by the Sanming University of PRC under Grant 20YG03S. 


\section{REFERENCES}

[1] A.K. Bhunia, and A.A. Shaikh, An application of PSO in a two-warehouse inventory model for deteriorating item under permissible delay in payment with different inventory policies. Appl. Math. Comput. 256 (2015) 831-850.

[2] P.N. Bloom and V.G. Perry, Retailer power and supplier welfare: the case of Wal-Mart. J. Retail. 77 (2001) 379-396.

[3] E. Cao and M. Yu, Trade credit financing and coordination for an emission-dependent supply chain. Comput. Ind. Eng. 119 (2018) 50-62.

[4] L.E. Cárdenas-Barrón, A.A. Shaikh, S. Tiwari and G. Treviño-Garza, An EOQ inventory model with nonlinear stock dependent holding cost, nonlinear stock dependent demand and trade credit. Comput. Ind. Eng. 139 (2020) 105557.

[5] S. Chand and J. Ward, A note on economic order quantity under conditions of permissible delay in payments. J. Oper. Res. Soc. 38 (1987) 83-84.

[6] C.T. Chang, J.T. Teng and S.K. Goyal, Inventory lot-size models under trade credits: a review. Asia Pac. J. Oper. Res. 25 (2008) 89-112.

[7] K.-J. Chung and J.-J. Liao, The simplified solution algorithm for an integrated supplier-buyer inventory model with two-part trade credit in a supply chain system. Eur. J. Oper. Res. 213 (2011) 156-165.

[8] K.-J. Chung, J.-J. Liao, P.-S. Ting, S.-D. Lin and H.M. Srivastava, A unified presentation of inventory models under quantity discounts, trade credits and cash discounts in the supply chain management. RACSAM 112 (2018) 509-538.

[9] S.C. Chen and J.T. Teng, Retailer's optimal ordering policy for deteriorating items with maximum lifetime under supplier's trade credit. Appl. Math. Model. 38 (2014) 4049-4061.

[10] B. Coulibaly, H. Sapriza and A. Zlate, Financial frictions, trade credit, and the 2008-09 global financial crisis. Int. Rev. Econ. Finance 26 (2013) 25-38.

[11] S.K. Goyal, Economic order quantity under conditions of permissible delay in payments. J. Oper. Res. Soc. 36 (1985) $335-338$.

[12] C.W. Haley and R.C. Higgins, Inventory policy and trade credit financing. Manage. Sci. 20 (1973) 464-471.

[13] C.-H. Ho, L.-Y. Ouyang and C.-H. Su, Optimal pricing, shipment and payment policy for an integrated supplier-buyer inventory model with two-part trade credit. Eur. J. Oper. Res. 187 (2008) 496-510.

[14] Y.H. Huang, Optimal retailer's ordering policies in the EOQ model under trade credit financing. J. Oper. Res. Soc. 54 (2003) 1011-1015.

[15] Y.-F. Huang and K.-J. Chung, Optimal replenishment and payment policies in the EOQ model under cash discount and trade credit. Asia Pac. J. Oper. Res. 20 (2003) 177-190.

[16] S. Krichen, A. Laabidi and F.B. Abdelaziz, Single supplier multiple cooperative retailers inventory model with quantity discount and permissible delay in payments. Comput. Ind. Eng. 60 (2011) 164-172.

[17] J.-J. Liao, K.-N. Huang, K.-J. Chung, S.-D. Lin, P.-S. Ting and H.M. Srivastava, Retailer's optimal ordering policy in the EOQ model with imperfect quality items under limited storage capacity and permissible delay. Math. Methods Appl. Sci. $\mathbf{4 1}$ (2018) 7624-7640.

[18] T.Y. Lin, Coordination policy for a two-stage supply chain considering quantity discounts and overlapped delivery with imperfect quality. Comput. Ind. Eng. 66 (2013) 53-62.

[19] T.-T. Lin and J.-H. Chou, Trade credit and bank loan: evidence from Chinese firms. Int. Rev. Econ. Finance 36 (2015) 17-29.

[20] A.K. Manna, B. Das, J.K. Dey and S.K. Mondal, Two layers green supply chain imperfect production inventory model under bi-level credit period. Tékhne 15 (2017) 124-142.

[21] L.-Y. Ouyang and K.-W. Chuang, Economic order quantity with allowable shortage and quantity discounts under permissible delay in payments. J. Inf. Opt. Sci. 25 (2004) 53-61.

[22] L.-Y. Ouyang, J.-T. Teng, K.-W. Chuang and B.-R. Chuang, Optimal inventory policy with non-instantaneous receipt under trade credit. Int. J. Prod. Econ. 98 (2005) 290-300.

[23] K.P. Pan, K.K. Lai, L. Liang and C.H. Leung, Two-period pricing and ordering policy for the dominant retailer in a two-echelon supply chain with demand uncertainty. Omega 37 (2009) 919-929.

[24] J.M. Ries, C.H. Glock and K. Schwindl, The influence of financial conditions on optimal ordering and payment policies under progressive interest schemes. Omega 70 (2017) 15-30.

[25] J.-T. Teng, Discount cash-flow analysis on inventory control under various supplier's trade credit. Int. J. Oper. Res. 3 (2006) $23-29$.

[26] J.T. Teng and C.T. Chang, Optimal manufacturer's replenishment policies in the EPQ model under two levels of trade credit policy. Eur. J. Oper. Res. 195 (2009) 358-363.

[27] S. Tiwari, L.E. Cárdenas-Barrón, A. Khanna and C.K. Jaggi, Impact of trade credit and inflation on retailer's ordering policies for non-instantaneous deteriorating items in a two-warehouse environment. Int. J. Prod. Econ. 176 (2016) 154-169.

[28] S. Tiwari, L.E. Cárdenas-Barrón, M. Goh and A.A. Shaikh, Joint pricing and inventory model for deteriorating items with expiration dates and partial backlogging under two-level partial trade credits in supply chain. Int. J. Prod. Econ. 200 (2018) $16-36$.

[29] S. Tiwari, L.E. Cárdenas-Barrón, A.A. Shaikh and M. Goh, Retailer's optimal ordering policy for deteriorating items under order-size dependent trade credit and complete backlogging. Comput. Ind. Eng. 139 (2020) 105559.

[30] Y.-C. Tsao, Trade credit and replenishment decisions considering default risk. Comput. Ind. Eng. 117 (2018) $41-46$.

[31] Vandana and B.K. Sharma, An EOQ model for retailer's partial permissible delay in payment linked to order quantity with shortages. Math. Comput. Simulat. 125 (2016) 99-112. 
[32] Z. Wang and S. Liu, Supply chain coordination under trade credit and quantity discount with sales effort effects. Math. Probl. Eng. (2018) 2190236, 1-15.

[33] M. Xue and J. Zhang, Supply chain encroachment with quality decision and different power structures. RAIRO:OR 54 (2020) 693-718.

[34] H. Yang, W. Zhuo, Y. Zha and H. Wan, Two-period supply chain with flexible trade credit contract. Expert Syst. Appl. 66 (2016) 95-105.

[35] H. Yang, L. Miao and C. Zhao, The credit strategy of a green supply chain based on capital constraints. J. Clean. Prod. 224 (2019) 930-939.

[36] Y.-W. Zhou and D. Zhou, Determination of the optimal trade credit policy: a supplier-Stackelberg model. J. Oper. Res. Soc. 64 (2013) 1030-1048.

[37] Y.-W. Zhou, Y.-G. Zhong and M.I.M. Wahab, How to make the replenishment and payment strategy under flexible two-part trade credit. Comput. Oper. Res. 40 (2013) 1328-1338.

[38] Y.-W. Zhou, Z.-L. Wen and X.-L. Wu, A single-period inventory and payment model with partial trade credit. Comput. Ind. Eng. 90 (2015) 132-145.

[39] X. Zou and B. Tian, Retailer's optimal ordering and payment strategy under two-level and flexible two-part trade credit policy. Comput. Ind. Eng. 142 (2020) 106317. 